\title{
A mutation in the Rho1-GAP-encoding gene BEM2 of Saccharomyces cerevisiae affects morphogenesis and cell wall functionality
}

\author{
Víctor J. Cid, Rosa Cenamor, Miguel Sánchez and César Nombela
}

Departamento de

Microbiologia II, Facultad de Farmacia, Universidad Complutense de Madrid, 28040 Madrid, Spain
Author for correspondence: Miguel Sánchez. Tel: +34 1 3941746. Fax: + 3413941745. e-mail: vicjcid@eucmax.sim.ucm.es

Saccharomyces cerevisiae strain V918 was previously isolated in a search for thermosensitive autolytic mutants and found to bear a recessive mutation that caused the development of multinucleate swollen cells undergoing cell lysis. The BEM2 gene has been isolated by complementation of the phenotype of a V918 segregant. BEM2 encodes a Rho-GTPase-activating protein (GAP) which is thought to act as a modulator of the Rho1 small GTPase. It is shown that the mutation causing the morphogenetic and autolytic phenotype in strain V918 and its segregants lies in the BEM2 gene, defining a new mutant allele, bem221. Mutants in the BEM2 gene have been reported to display loss of cell polarity and depolarization of the actin cytoskeleton, causing a bud-emergence defect. Low resistance to sonication and to hydrolytic enzymes proved that the cell wall is less protective in bem2-21 mutants than in wild-type strains.

Moreover, bem2-21 mutants are more sensitive than the wild-type to several antifungal drugs. Transmission electron microscopy revealed the development of abnormally thick and wide septa and the existence of thin areas in the cell wall which probably account for cell lysis. The depolarization of actin in bem221 mutants did not preclude morphogenetic events such as cell elongation in homozygous diploid strains during nitrogen starvation in solid media, hyperpolarization of growth in a background bearing a mutated septin, or sporulation. Multinucleate cells from bem2-21 homozygous diploids underwent sporulation giving rise to multispored asci ('polyads'), containing up to 36 spores. This phenomenon occurred only under osmotically stabilized conditions, suggesting that the integrity of the ascus wall is impaired in cells expressing the bem2-21 mutation. It is concluded that the function of the BEM2 gene product is essential for the maintenance of a functional cell wall.

Keywords: Saccharomyces cerevisiae, Rho-GAP, cell integrity, morphogenesis, cell wall

\section{INTRODUCTION}

The fungal cell wall is responsible for cell shape and protection of the cell against environmental changes. Yeast cells lacking a functional wall may eventually lose their integrity, undergoing lysis unless they are grown under osmotically stabilized conditions. The yeast cell wall consists of a polysaccharide matrix (mainly constituted by $1,3-\beta$-glucan but also containing $1,6-\beta$-glucan and chitin) to which a complex set of glycoproteins is attached (Klis, 1994; Cid et al., 1995). The shaping of fungal cells depends on cell surface rearrangements.
Growing areas are supported by complex cytoskeletal actin-based structures that determine the polarization of the secretion machinery towards that point (Mulholland et al., 1994). The development of a functional cell wall must depend not only on the correct function of biosynthetic enzymes but also on the correct establishment of such actin-dependent polarized secretion. It can be hypothesized that the molecular mechanisms controlling cytoskeletal rearrangements at the cell surface level in response to cell-cycle-dependent or environmental signals and those which control cell integrity obey common signals and may even share common pathways.

The best example of the integration of morphogenetic 
signal transduction elements and cell wall biogenesis has been given by Drgonová et al. (1996) and Qadota et al. (1996), who defined the small Rho-type GTPase Rho1 as a regulatory subunit of the 1,3- $\beta$-glucan synthase complex. Rho proteins are generally involved in the signalling events that lead to the assembly of actin filaments in response to different stimuli in eukaryotes (Ridley, 1995). In budding yeast, the polarization of actin towards a preselected bud-emergence site seems to be monitored by the Rho-related GTPase Cdc42, while the maintenance of bud growth - after the onset of bud emergence - depends on Rho1 (Yamochi et al., 1994). In addition, Rho1 seems to interact with the only protein kinase $\mathrm{C}$ described in the budding yeast, namely Pkc1 (Nonaka et al., 1995), thus activating a Pkc1-dependent MAP kinase phosphorylation cascade whose function is important for cell integrity (Lee et al., 1993; Martin et al., 1993).

Small GTPases, such as the Rho proteins, are activated when bound to GTP and lack any activity when bound to GDP. Hence, the regulation of the GTP/GDP cycle in these proteins is the key for the understanding of their regulation. Three kinds of proteins have been described as the regulators of the binary switch of these small GTPases, namely GEPs, GDIs and GAPs. GEP stands for GDP/GTP exchange protein, a type of protein that favours the GTP-bound conformation of these small G proteins, thus leading to their activation. The GEP for Cdc42 is the putative $\mathrm{Ca}^{2+}$-binding protein $\mathrm{Cdc} 24$ (Zheng et al., 1994), while the GEPs for Rho1 are encoded by the redundant genes ROM1 and ROM2 (Ozaki et al., 1996). Recently, Rom2 has been reported to be activated by the phosphatidylinositol kinase encoded by the TOR2 gene (Schmidt et al., 1997). GDIs (guanine nucleotide dissociation inhibitors) inhibit the GDP/GTP exchange reaction catalysed by GEPs. Rdi1, the only GDI reported so far in Saccharomyces cerevisiae (Masuda et al., 1994), has been shown to inhibit Rom2 activity over Rho1 (Ozaki et al., 1996). GAP stands for GTPase-activating protein; the role of these proteins is the opposite to that of GEPs, namely to activate the GTPase function of Rho proteins, thus generating the non-functional GDP-bound form. Two GAPs are known for Cdc42, encoded by the genes BEM3 and RGA1/DBM1 (Stevenson et al., 1995; Chen et al., 1996), while the GAPs reported for Rho1 are encoded by the SAC7 and BEM2 genes (Peterson et al., 1994; Schmidt et al., 1997).

Both overexpression of the $\mathrm{RHO} 1$ gene and disruption of BEM2 cause an actin depolarization phenotype reminiscent of that observed in $c d c 42$ and $c d c 24$ mutants (Bender \& Pringle, 1991; Yamochi et al., 1994), which might suggest that GTP-bound $\mathrm{Cdc} 42$ may activate Bem2 for the inhibition of Rho1 until its function is required later in the cell cycle. BEM2 has also been described to show genetic interactions with genes related to cytoskeletal function, such as those encoding tropomyosin (Tpm1), unconventional myosin (Myo2), actin (Act1) and fimbrin (Sac6) (Wang \& Bretscher, 1995), and the actin-binding protein Bem1 (Peterson et al.,
1994), as well as with other genes related to morphogenetic control such as SPA2 (M. Snyder, personal communication) and CDC55, encoding a type $2 \mathrm{~A}$ protein phosphatase B regulatory subunit (Healy et al., 1991).

The isolation of autolytic mutants is a classical approach towards the understanding of the genetic control of cell wall function and the dynamics of cell wall biogenesis (Cabib \& Duran, 1975). Mutants affected in the abovementioned mechanisms, such as those with mutations in genes that belong to the Pkc1-led MAP kinase cascade and Rho1, display an autolytic phenotype (Torres et al., 1991; Paravicini et al., 1992; Yamochi et al., 1994). In a previous study we isolated 34 mutants affected in cell integrity, most of which additionally displayed morphogenetic defects (Cid et al., 1994). One of those mutants, strain V918, developed an interesting fragile phenotype with the occurrence of round multinucleate cells filled with large vacuoles. In the present report we conclude that strain V918 defines a novel mutant allele of the BEM2 gene. We have analysed the cytological consequences of the bem 2 mutation and its impact on cell wall function.

\section{METHODS}

Yeast strains, growth media and culture conditions. V918 is a mutant strain derived from strain D1 (a/ $\alpha$ ura3/ura 3 leu2/leu2 trp1 bis3 his4). Strains 918-8a, 918-8c and 918-5c originated from first-offspring segregants from V918. Strain 918-5b-3b-5c-7b is a Ura- fourth-generation segregant of V918 obtained after mating segregants of the first and second offspring to strain 373 ( $\alpha$ ade2) and a segregant from the third offspring to strain 1784 (a ura3 leu2 trp1 his 4 can ${ }^{\mathrm{R}}$ ). Strains Y806 (a ura3 leu2 ade 2 ade 3 lys $2 \rho^{\circ}$ ) and Y807 ( $\alpha$ bem $2:: U R A 3$ ura3 leu 2 ade 2 ade3 lys $2 \rho^{\circ}$ ) were kindly provided by Dr A. Bender (Indiana University, Bloomington, IN, USA). Strains Y527 ( $\alpha$ cdc10-1 ade1 ade2 ura1 leu2) and Y882 ( $\alpha$ cdc10::URA3 ura3 lys2 ade2 his3 trp1) were provided by Dr. M. Snyder (Yale University, New Haven, CT, USA). Control wild-type strains used in some experiments were S288C ( $\alpha$ gal2) and TD28 (a ura3 ino1 can ${ }^{\mathrm{R}}$ ).

Cells were grown in $250 \mathrm{ml}$ flasks containing (for general purposes $) 50 \mathrm{ml} \mathrm{YED}(2 \%, \mathrm{w} / \mathrm{v}$, glucose; $1 \%$ yeast extract $)$ or (for plasmid maintenance) SD (1.7 g Difco nitrogen base without amino acids $1^{-1} ; 0.5 \%, \mathrm{w} / \mathrm{v}$, ammonium sulphate; $2 \%, w / v$, glucose) plus the required mixture of amino acids; or in culture tubes with $5 \mathrm{ml}$ of the same media. Solid media were based on the same formula plus $2 \%(w / v)$ agar. Growth temperatures were $24^{\circ} \mathrm{C}$ for general purposes and $37^{\circ} \mathrm{C}$ for the expression of lytic phenotype in mutant strains. BCIP (5bromo-4-chloro-3-indolylphosphate, Sigma), $40 \mathrm{mg} \mathrm{l}^{-1}$, was added to the media to detect cell lysis (Cid et al., 1994) when required. To induce sporulation of diploids, cells were first grown on solid PSM $(1 \%, \mathrm{w} / \mathrm{v}$, yeast extract; $3 \%, \mathrm{w} / \mathrm{v}$, meat extract; $5 \%, \mathrm{w} / \mathrm{v}$, glucose) and transferred to SM $(1 \%, \mathrm{w} / \mathrm{v}$, potassium acetate; $0.1 \%, \mathrm{w} / \mathrm{v}$, yeast extract $; 0.025 \%$ glucose) or SSM (1 M sorbitol; $1 \%$, w/v, potassium acetate; $0.1 \%$, $\mathrm{w} / \mathrm{v}$, yeast extract; $0.025 \%$ glucose) and incubated at $24^{\circ} \mathrm{C}$. Nitrogen starvation SLADH plates were prepared as described by Gimeno et al. (1992).

Flow cytometry, fluorescence microscopy and electron microscopy. Cell size and granularity of cell populations were determined by forward scatter and side scatter respectively in 
a FACScan flow cytometer (Becton-Dickinson); 5000 cells were analysed per sample. Chromomycin staining for the visualization of nuclei under fluorescence microscopy was performed as previously described (Cid et al., 1994). For transmission electron microscopy, cells were pre-fixed with a glutaraldehyde solution for $24 \mathrm{~h}$ as described by Miret et al. (1992) and then fixed with $1.5 \%(\mathrm{w} / \mathrm{v})$ potassium permanganate for $60 \mathrm{~min}$ at $4{ }^{\circ} \mathrm{C}$. Fixed cells were carefully washed with water several times and then dehydrated in graded acetone concentrations $(30,40,50,60,70,80,90$ and $100 \%$, $\mathrm{v} / \mathrm{v}, 15 \mathrm{~min}$ in each). Samples were embedded in Epon 812 resin (Electron Microscopy Sciences) following the supplier's instructions. The solid product was cut into ultrathin slices with an Ultracut machine, treated with lead citrate and uranyl acetate and observed in a JEOL 1010 electron microscope.

Disintegration of yeast cells by sonication. An MSE Soniprep 150 was used to test the resistance of yeast cells to ultrasonic waves. The probe was sterilized with $80 \%(\mathrm{v} / \mathrm{v})$ ethanol. A sample of $2 \times 10^{5}$ cells was suspended in $10 \mathrm{ml}$ sterile water, placed in the sonication tube over ice and treated with a wave amplitude of $6 \mu \mathrm{m}$ several times at intervals of $1 \mathrm{~min}$. Duplicate $50 \mu \mathrm{l}$ samples from the suspension treated during $0-5 \mathrm{~min}$ were plated on YED plates and incubated for $3 \mathrm{~d}$ at $24^{\circ} \mathrm{C}$. After counting the resulting colonies, the mean data from the two plates gave the survival rate after a given exposure time.

Assay for resistance to hydrolytic enzymes. A sample of $2 \times 10^{6}$ cells was collected and resuspended in $0 \cdot 1 \mathrm{ml}$ sterile water. Zymolyase $\left(0.5 \mathrm{mg} \mathrm{m}^{-1}\right.$; Seikagaku Corporation) was added and the tubes were incubated at room temperature for various times. Then $10 \mu$ l of suspension was diluted $1 / 1000$ with sterile water and duplicate $50 \mu \mathrm{l}$ samples of this suspension were plated on YED medium. After $3 \mathrm{~d}$ incubation at $24^{\circ} \mathrm{C}$ the resulting colonies were counted; the mean data gave the survival rate after each given exposure time.

Assays of susceptibility to antifungal drugs. The following antifungal drugs were used at the concentrations indicated: trichodermol (Lovens), nikkomycin (provided by Glaxo), echinocandin B and papulacandin B (kindly provided by A. Durán), cilofungin (provided by Lilly), Calcofluor white (Fluorescent Brightener 28, Sigma), ketoconazole (Sigma), benomyl (Chem Service), polymyxin B (Sigma), amphotericin B (Sigma), 5-fluorocytosine (Sigma) and tunicamycin (Sigma). Susceptibility assays to echinocandin, papulacandin, tunicamycin and sodium orthovanadate were performed in 96-well sterile plates, by filling each well with $200 \mu \mathrm{l}$ SD medium containing decreasing concentrations of drug, ranging from 200 to $0.8 \mu \mathrm{g} \mathrm{ml}^{-1}$, and inoculating it with approximately $10^{3}$ cells. After $24 \mathrm{~h}$ incubation at $24^{\circ} \mathrm{C}$, the $\mathrm{OD}_{600}$ of each well was determined. Sensitivity to other drugs was determined by incubation in YED plates to which a given amount of drug had been added.

Molecular biology techniques. Escherichia coli transformation and other molecular biology techniques were performed as described by Sambrook et al. (1989) and Ausubel et al. (1993). Restriction endonucleases and other enzymes were provided by Boehringer Mannheim. Introduction of plasmids into yeast cells was carried out by the one-step lithium acetate method. Plasmids used in this work were pRS316 (Sikorski \& Hieter, 1989) and the genomic library provided by Dr Craig Thompson (Whitehead Institute, Cambridge, MA, USA), containing 8-12 kb DNA fragments in the Xhol site of plasmid pCT3, a derivative of pUN55 (Elledge \& Davis, 1988).

\section{RESULTS}

\section{Cell size alterations in strain V918}

The autolytic mutant strain V918 had been previously shown to develop abnormally large cells, often multinucleate (Cid et al., 1994). Genetic analyses of this strain proved that it carried a single recessive mutation in homozygosis, that we named lyt3. The severity of the lyt 3 morphogenetic and lytic phenotype depended strongly on the genetic background of each segregant. Regardless of the variable expression of the characteristic swollen phenotype, we observed that a clear $2: 2$ segregation of lyt $3: L Y T 3$ could be followed on the basis of a loss-of-polarity phenomenon. The occurrence of a random budding pattern always co-segregated with more or less severe cell lysis and cell enlargement phenotypes after four generations of crosses with wildtype strains 373 and L839. Another feature of these mutant segregants was the heterogeneity in size and granularity (a parameter that gives information about cellular complexity in terms of shape) that could be
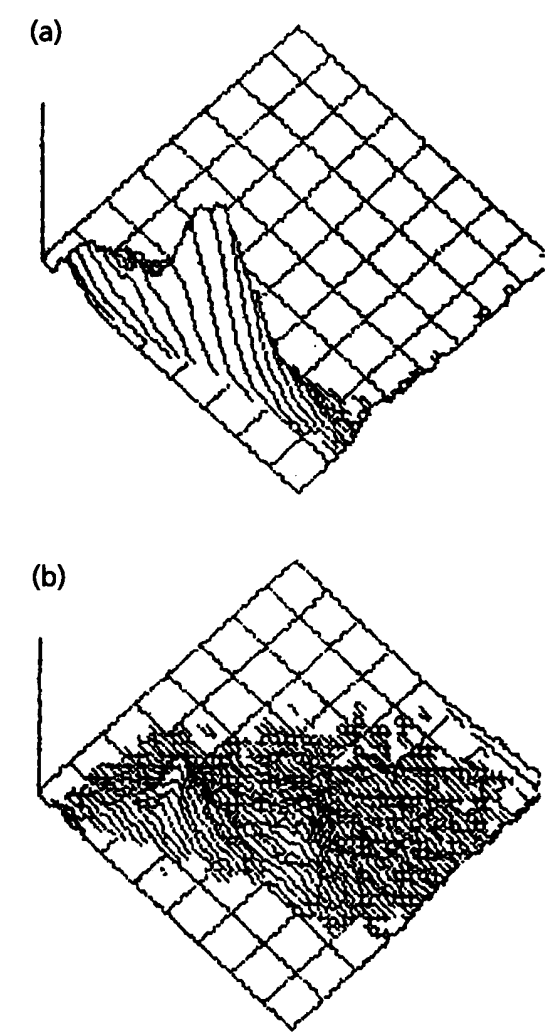

Fig. 1. Biparametric graphics after FACS analysis of strains D1 (wild-type; a) and V918 (b) grown at $37^{\circ} \mathrm{C}$ for $5 \mathrm{~h}$. Cell size (forward scatter) is represented on the $x$ axis; cell complexity or granularity (side scatter) is represented on the $y$ axis. Lateral scattering of the incident beams on the cell should give an indication of irregularities on its surface, such as ruffled or 'bumpy' areas or the presence of buds. The $z$ axis represents the number of cells. The wild-type strain D1 displays a rather homogeneous distribution of cell size and complexity, while the v918 mutant population shows significant variability regarding both parameters. 
Table 1. Growth of diploid and haploid /yt3 and wild-type strains on plates supplemented with different antifungal compounds

Growth of the strains was evaluated in drops over YED plates plus antifungals. +++ , Normal growth; ++ , slow or limited growth; + , very poor growth; \pm , extremely poor growth; - , no growth at all; ND, not determined.

\begin{tabular}{|c|c|c|c|c|c|}
\hline Antifungal & D1 & V918 & $918-5 b-3 b-5 c-7 b$ & S288C & TD28 \\
\hline Control $28^{\circ} \mathrm{C}$ & +++ & +++ & +++ & +++ & +++ \\
\hline Control $37^{\circ} \mathrm{C}$ & +++ & ++ & +++ & +++ & +++ \\
\hline Trichodermol $\left(1 \mu \mathrm{g} \mathrm{ml}^{-1}\right) 28^{\circ} \mathrm{C}$ & +++ & + & + & +++ & +++ \\
\hline Nikkomycin $\left(0.5 \mathrm{mg} \mathrm{ml}^{-1}\right) 37^{\circ} \mathrm{C}$ & ++ & \pm & \pm & +++ & ++ \\
\hline Papulacandin B $\left(2 \mu \mathrm{g} \mathrm{ml}^{-1}\right) 28^{\circ} \mathrm{C}$ & +++ & + & + & +++ & +++ \\
\hline Cilofungin $\left(0.2 \mathrm{mg} \mathrm{ml}^{-1}\right) 28^{\circ} \mathrm{C}$ & +++ & - & - & +++ & ++ \\
\hline Cilofungin $\left(0.2 \mathrm{mg} \mathrm{ml}^{-1}\right) 37^{\circ} \mathrm{C}$ & + & - & - & +++ & +++ \\
\hline Echinocandin B $\left(10 \mu \mathrm{g} \mathrm{ml}^{-1}\right) 28^{\circ} \mathrm{C}$ & +++ & - & - & +++ & +++ \\
\hline Echinocandin $\mathrm{B}\left(10 \mu \mathrm{g} \mathrm{ml}^{-1}\right) 37^{\circ} \mathrm{C}$ & ++ & - & - & +++ & ++ \\
\hline Ketoconazole $\left(0.1 \mathrm{mg} \mathrm{ml}^{-1}\right) 28^{\circ} \mathrm{C}$ & +++ & - & - & +++ & +++ \\
\hline Amphotericin B $\left(20 \mu \mathrm{g} \mathrm{ml}^{-1}\right) 28^{\circ} \mathrm{C}$ & +++ & ++ & - & +++ & - \\
\hline Polymyxin B $(0.5 \mathrm{mM}) 28^{\circ} \mathrm{C}$ & +++ & - & ND & +++ & +++ \\
\hline Calcofluor white $\left(20 \mu \mathrm{g} \mathrm{ml}^{-1}\right) 28^{\circ} \mathrm{C}$ & $++t$ & $++t$ & - & +++ & +++ \\
\hline Calcofluor white $\left(20 \mu \mathrm{g} \mathrm{m}^{-1}\right) 37^{\circ} \mathrm{C}$ & ++ & - & - & +++ & +++ \\
\hline 5-Fluorocytosine $\left(20 \mu \mathrm{g} \mathrm{ml}^{-1}\right) 28^{\circ} \mathrm{C}$ & ++ & - & \pm & +++ & ++ \\
\hline Benomyl $(1 \mathrm{mM}) 28^{\circ} \mathrm{C}$ & +++ & + & - & +++ & +++ \\
\hline
\end{tabular}

detected by, respectively, forward-scatter and sidescatter flow cytometry analyses. The remarkable dispersion displayed by the original diploid V918 strain differed from the clear peak distribution of the isogenic wild-type D1 strain, as shown in Fig. 1. The same diversity of cell size and granularity was observed in all the loss-of-polarity segregants belonging to the 918 series (data not shown).

\section{Susceptibility of strain V918 to some antifungal drugs}

Drops containing about $10^{5}$ cells of the diploid strain V918, its isogenic wild-type D1, the fourth-generation haploid segregant $918-5 b-3 b-5 c-7 b$ and wild-type haploids S288C and TD28 were tested against different antifungal drugs added to YED agar plates. Previous experiments had determined the highest drug concentration that allowed efficient growth of strain D1. As shown in Table 1, lyt 3 mutants were more sensitive than the wild-type to a great variety of antifungal compounds, especially to those that interfere with cell wall biosynthesis, such as nikkomycin, papulacandin B, cilofungin and echinocandin $B$, but also to others acting on intracellular targets, such as ketoconazole, benomyl and 5 -fluorocytosine, or on the plasma membrane, such as amphotericin and polymyxin. This may reflect an increase in the permeability of the cell surface, due to quantitative or qualitative changes in the composition of the cell wall or the plasma membrane. The results obtained with strains V918 and $918-5 b-3 b-5 c-7 b$ were very similar, indicating that the lyt 3 mutation is probably the only one responsible for the multiple-drug hypersensitivity phenotype. Nevertheless, the original V918 strain may bear some additional background mutations, since its hypersensitivity to caffeine did not co-segregate with the random budding and lytic phenotypes. In fact, strain $918-5 b-3 b-5 c-7 b$ was not caffeinesensitive (data not shown).

lyt 3 mutants display a more severe swollen phenotype and cell lysis at $37^{\circ} \mathrm{C}$ than at $28^{\circ} \mathrm{C}$, so sensitivity to some drugs was tested at both temperatures. As can be seen from Table 1, the inhibition of growth caused by the different antifungal compounds was already evident at the standard growth temperature of $28^{\circ} \mathrm{C}$. The sensitivity of the mutants to these compounds at a nonrestrictive temperature suggests that access of the drugs to their targets is favoured by the lyt 3 mutation even in conditions that do not strongly compromise morphogenesis. The increased susceptibility of the mutant to all these drugs with such different targets probably indicates an increased permeability (thus facilitating the access of the molecules to the targets), rather than an alteration of the targets themselves.

The sensitivity to echinocandin and papulacandin, which interfere with $1,3-\beta$-glucan synthesis, was studied further. MICs of both these antifungal drugs for strains D1 and V918 were determined (Table 2). The wild-type strain required approximately twice the concentration of these substances for growth inhibition compared with the mutant. The results were similar when strains Y807 (bem2::URA3) and Y806 (an isogenic wild-type) were tested (data not shown). The lyt 3 mutant also showed some hypersusceptibility to sodium orthovanadate and tunicamycin (Kuo \& Lampen, 1974; Ballou et al., 1991) 
Table 2. MICs (determined in microtitre plates) of drugs that interfere with $\beta$-glucan synthesis or protein glycosylation, for the wild-type D1 and mutant V918 strains

\begin{tabular}{|lcccc|}
\hline Strain & \multicolumn{4}{c|}{ MIC $\left(\mu \mathrm{g} \mathrm{ml}^{-1}\right)$} \\
\cline { 2 - 5 } & Echinocandin B & Papulacandin B & Orthovanadate & Tunicamycin \\
\hline D1 $\left(28^{\circ} \mathrm{C}\right)$ & 25 & 25 & 125 & 15 \\
V918 $\left(28^{\circ} \mathrm{C}\right)$ & 12.5 & $<12.5$ & $<62.5$ & 3 \\
\hline
\end{tabular}

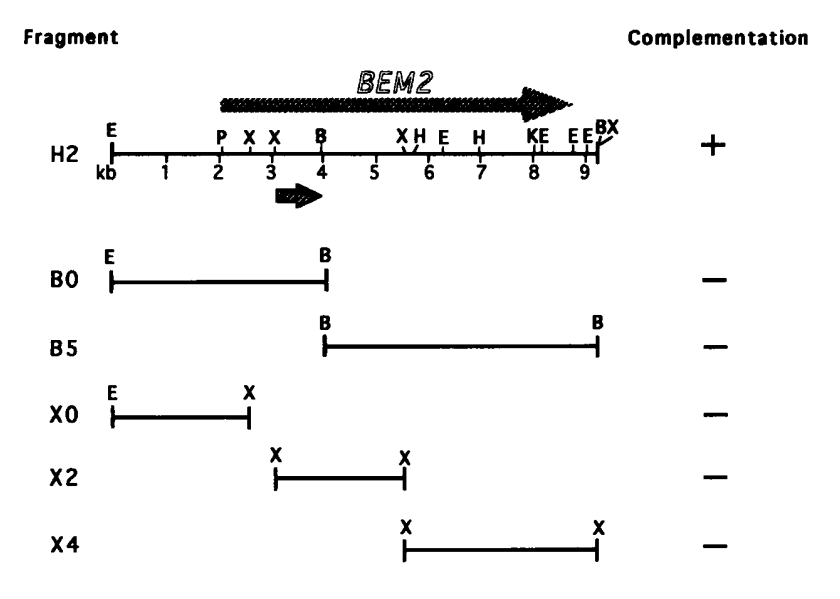

Fig. 2. Complementation of $918-5 b-3 b-5 c-7 b$ (ura3 /yt3) swollen cells and lytic phenotypes by subclones of the $9.3 \mathrm{~kb}$ insert isolated from the genomic library screening. Only the whole insert was able to complement. Plasmid pRS316 was transformed in parallel as a negative control for complementation. The small arrow indicates the $0.9 \mathrm{~kb}$ $X$ bal-BamHI fragment that we sequenced and found homologous to the $B E M 2$ gene, its coding region lying in the original insert as indicated. E, ECoRI; P, Pstl; X, Xbal; B, BamHI; H, HindIII; K, Kpnl.

(Table 2), which are inhibitors of protein glycosylation, a process that is obviously crucial-among other important physiological implications - for the production of cell wall glycoproteins.

\section{The BEM2 gene complements the lyt3 mutation}

A library in a centromeric vector bearing $S$. cerevisiae genomic DNA fragments of $8-12 \mathrm{~kb}$ was screened on strain $918-5 b-3 b-5 c-7 b$. This strain could not grow on media containing echinocandin B. Approximately 100000 transformants were replica-plated to SD plates lacking uracil, supplemented with $20 \mu \mathrm{g}$ echinocandin B $\mathrm{ml}^{-1}$ and $40 \mathrm{mg} \mathrm{BCIP}$ (5-bromo-4-chloro-3-indolyl phosphate, Sigma) $\mathrm{ml}^{-1}$ to facilitate selection of those clones that displayed reduced cell lysis (lysing colonies turn blue in the presence of this substrate: Cid et al., 1994). Plates were incubated at $37^{\circ} \mathrm{C}$ for $2-3 \mathrm{~d}$ and then the 500 best-growing white clones were selected. Each of these clones was grown overnight in $5 \mathrm{ml}$ liquid SD medium lacking uracil at $24^{\circ} \mathrm{C}$, switched to $37^{\circ} \mathrm{C}$ for 3-4 $\mathrm{h}$ and observed under a phase-contrast microscope to select clones that showed a homogeneous wild-type- like cell size. Two of these clones did not show the abnormal round enlarged shape or cell lysis and their budding pattern was axial instead of random.

Plasmid extraction from both clones and retransformation of the rescued vectors (pCT3-H2 and pCT3$\mathrm{X} 23$ ) to the same strain, to the original V918 diploid and to other ura 3 lyt 3 segregants proved that the inserts complemented the morphogenetic and autolytic phenotypes in all cases. Restriction analysis revealed that both clones contained an identical $9.3 \mathrm{~kb}$ DNA fragment. This fragment gave rise to two smaller segments after $B a m \mathrm{HI}$ cleavage and to three different segments by $\mathrm{XbaI}$ cleavage (Fig. 2). None of the subclones was able to complement the phenotype of lyt 3 mutants when included in the centromeric vector pRS316 or in pCT3. A $0.9 \mathrm{~kb} \mathrm{XbaI-BamHI}$ fragment was sequenced in both directions, revealing the presence in the original insert of the complete open reading frame of the BEM2 gene, which comprises 6572 bp (Kim et al., 1994; Peterson et al., 1994).

To test whether the lyt 3 mutation lay in the BEM2 locus, as the complementation of the pleiotropic lyt3 phenotype by the $B E M 2$ gene in a centromeric plasmid suggested, strain 918-8a (lyt3) was mated to Y807 (bem2::URA3). The diploids obtained from that cross displayed fragility, cell enlargement, multinucleation and loss of polarity, a phenotype identical to that of the V918 lyt $3 /$ lyt 3 homozygous strain. Tetrad analyses from such diploids revealed a 4:0 pattern of segregation of the loss of polarity and morphogenetic phenotype. We concluded from these experiments that the lyt 3 mutation actually defines a novel mutant allele in the BEM2 gene, which we will refer to as bem2-21.

\section{A bem2-21/bem2-21 diploid strain gives rise to 'polyads'}

bem2 (ipl2) mutants had been isolated in a search for mutations that cause an increase in ploidy (Chan $\&$ Botstein, 1993), consistent with our observation that V918 cells were often multinucleate (Cid et al., 1994). After chromomycin staining, we found that the V918 (bem2-21/bem2-21) strain displayed the following distribution of nucleation after $5 \mathrm{~h}$ at restrictive temperature: $3 \%$ of the cells had four nuclei or more; $9 \%$ had three nuclei; $21 \%$ had two nuclei in the same cellular compartment; $62 \%$ had a normal distribution of nuclei; and $5 \%$ seemed to lack a nucleus, since they 

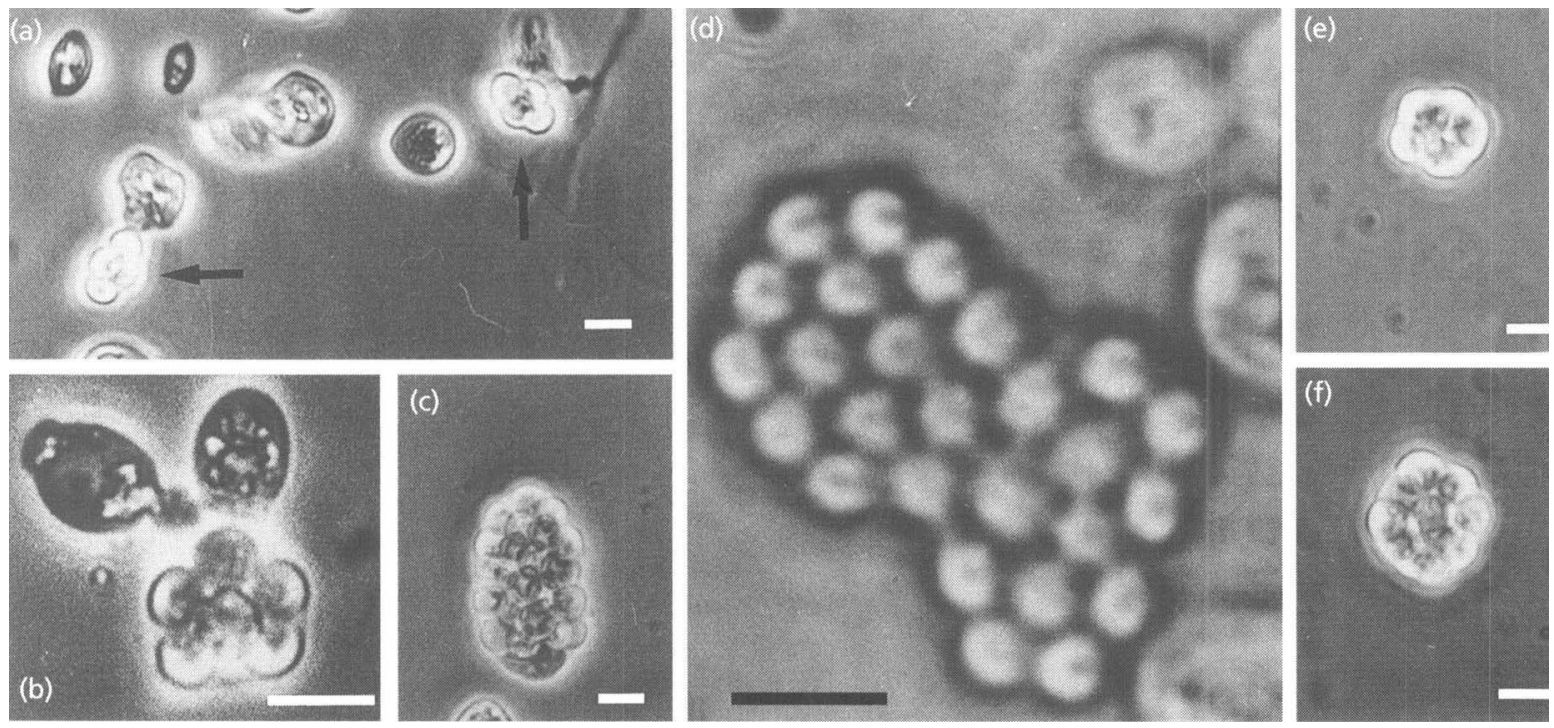

Fig. 3. Microscopic observation of 'polyads' from strain V918 under sporulation conditions lacking sorbitol (a) and in the presence of this osmotic stabilizer $(b-f)$. Sporulation of this strain in normal conditions gives rise to normal tetrads (a, arrows), while the addition of $1 \mathrm{M}$ sorbitol leads to asci containing 8 (b, e), 12 (f) or more (c, d) spores. Bars represent $5 \mu \mathrm{m}$.

were not stained by the fluorochrome. Sporulation of strain V918 in poor media gave rise to normal tetrads, although frequently attached to aborted buds.

Sorbitol (1 M) partially rescued cells from lysis (the percentage of lysed cells decreased from $90 \%$ to $50 \%$ after $5 \mathrm{~h}$ incubation at $37^{\circ} \mathrm{C}$ ) in the V918 autolytic strain and it was described by Kim et al. (1994) that $1 \mathrm{M}$ sorbitol could partially rescue growth of bem 2 mutants in solid media. We have also observed that growth at $37^{\circ} \mathrm{C}$ of bem $2-21$ mutants in media containing sorbitol allowed the development of gigantic cells, their diameter being often more than 10 times the average (data not shown). When we performed the sporulation experiments in media supplemented with this osmotic stabilizer, about $30 \%$ of the asci contained 8,12 or more spores (Fig. 3) (up to 35 spores were analysed from a single large ascus). These multispored asci, which we named 'polyads', appeared in sorbitol concentrations higher than $0.5 \mathrm{M}$. $\mathrm{CaCl}_{2}(0.1 \mathrm{M})$ was also tested as an alternative osmotic stabilizer, but 'polyads' were seldom observed and they never had more than eight ascospores. 'Polyad' formation was observed in every bem2/bem 2 homozygous strain tested, but never in bem $2 / B E M 2$ heterozygous strains, and this phenotype was complemented by plasmid pCT3-H2 containing the $B E M 2$ gene. Dissection of the 'polyads' revealed that ascospores from these aberrant asci were as viable and able to germinate as those dissected from normal tetrads.

\section{Weakness of the cell wall in bem2-21 mutants}

The fact that sorbitol allowed sporulation of multinucleate cells, which presumably are strongly expressing the bem2-21 phenotype, suggests that the ascus wall is not protective enough to support the sporulation process in osmotically non-stabilized media. This observation, the sensitivity to drugs interfering with cell wall biogenesis, and the remarkable cell lysis, especially at $37^{\circ} \mathrm{C}$, exhibited by the bem2-21 mutants, led us to test the protective ability of their cell wall. For this purpose, we performed experiments to test the resistance of the cells to the effects of cell-wall-hydrolytic enzymes and sonication.

Exposure of V918 and the isogenic wild-type strain D1 to a hydrolytic complex rich in glucanases (e.g. Zymolyase) gave the results shown in Fig. 4(a, b). The loss of viability for a given incubation time was quicker in the mutant than in the wild-type strain. For instance, after 10 min incubation of exponential-phase cells with the complex, half the population of the wild-type strain remained viable while less than $10 \%$ of the mutant did so. Transformation of strain V918 with the BEM2containing plasmid $\mathrm{pCT} 3-\mathrm{H} 2$ gave results indistinguishable from those obtained with strain D1 (data not shown), indicating that cell wall lability was due to the bem2-21 mutation. The experiment was also performed with cells in stationary phase. Resistance of both mutant and wild-type strains to Zymolyase treatment was much greater than that observed in exponential-phase cells, but the mutant strain lost viability in $50 \%$ of the cell population after a $10 \mathrm{~min}$ treatment while $80 \%$ of the cells from strain D1 remained viable after $3 \mathrm{~h}$ incubation with the enzyme.

Disintegration of cells by sonication gave results similar to those of the Zymolyase experiment (Fig. 4c). Loss of viability with increasing sonication time was less dra- 

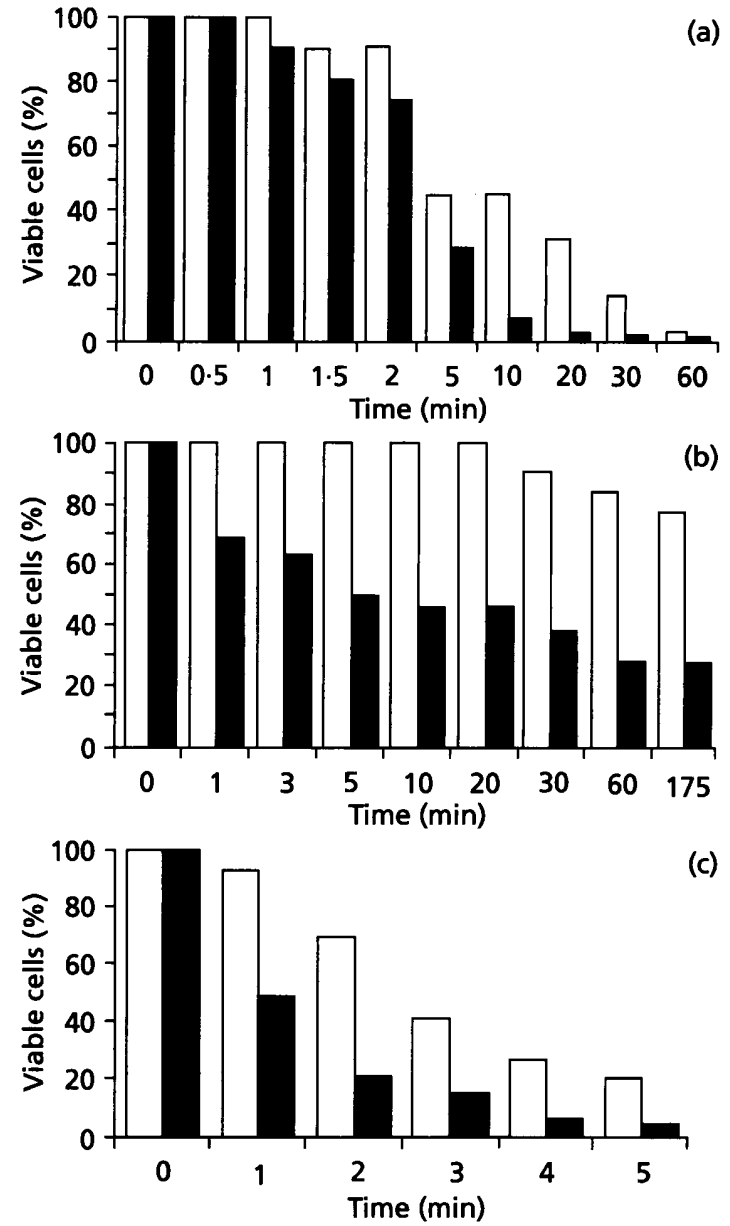

(c)

Fig. 4. (a, b) Loss of viability upon treatment with Zymolyase of cells in the mid-exponential phase (a) and stationary phase (b) from strain V918 (black bars) and the isogenic wild-type D1 (white bars). (c) The same rationale applied to a sonication treatment. The percentage of surviving cells was calculated taking as $100 \%$ the survival determined just before the addition of Zymolyase or commencement of sonication.

matic in the wild-type than in the bem2-21 homozygous mutant.

\section{Local alterations of cell wall architecture in bem2-21}

Strain V918 was compared with wild-typre strain D1 by thin-section electron microscopy. These experiments confirmed the appearance of large round cells containing several nuclei and showing a random budding pattern (Fig. 5f). The occurrence of abnormally thick or wide septa was often observed (Fig. 5b, c, e, g), consistent with the detection of chitin-rich areas near the septum area by Calcofluor staining (Fig. 6d). Bud scars were randomly distributed along the cell surface and heterogeneous in size (Fig. 6b, c), probably due to the progress of cytokinesis in non-constricted areas (Fig. $5 \mathrm{~b}, \mathrm{c}, \mathrm{e}, \mathrm{g})$. Occasionally, small buds were formed and released from a huge mother cell (Fig. $5 c, e, g)$. Ap- parently, nuclei were never present in these small daughter cells so they probably correspond to the nonnucleated fraction of the population detectable by fluorescence microscopy (see above), which had previously been reported to exist in a bem $2 / i p l 2$ mutant by Chan \& Botstein (1993).

Weak areas in the cell wall were detected in lysed and non-lysed cells (Fig. 5b,d). These areas consist of an unusually narrow electron-translucent glucan layer and a diminished or absent external mannan layer, which causes a local swelling (Fig. 5b). It seems reasonable to speculate that the existence of such weak zones in the cell wall is the cause of cell lysis.

\section{Growth depolarization in bem2-21 mutants does not exclude hyperpolarization phenomena}

All data provided so far on the BEM2 gene support the hypothesis that the phenotype of mutants affected in the gene is due to a depolarization of growth; that is, development is not restricted to the budding site but occurs throughout the whole cell surface, promoting isotropic growth of the mother cell (Bender \& Pringle, 1991; Kim et al., 1994; Peterson et al., 1994). Such behaviour is reminiscent of other bud-emergence mutants, such as $c d c 42, c d c 24$ and bem1 (Sloat et al., 1981; Adams et al., 1990; Bender \& Pringle, 1991). Unlike $c d c 42^{\text {ts }}$ and $c d c 24^{\text {ts }}$ mutants (Adams et al., 1990), our bem2-21 mutant strains can bud occasionally at the nonpermissive temperature, although buds are often abnormal, the result of this being cell populations that are quite heterogeneous in size (see above). A bem 2 deletant, the strain Y807 (Peterson et al., 1994), showed a more homogeneous swollen phenotype, and its growth at $37^{\circ} \mathrm{C}$ and lower temperatures was slower than that of any bem2-21 strain; however, budded cells were frequently observed (at least $30 \%$; data not shown), suggesting that the BEM2 gene is important but not indispensable for the polarization of growth. We tested whether situations in which hyperpolarization of growth occurs, such as the disassembly of the septin ring or pseudohyphal growth, would be maintained in a bem221 background.

Double bem2-21 cdc10-1 and bem2-21 cdc10::URA3 mutants were constructed by mating, respectively, strain Y527 to strain $918-8$ a and strain Y882 to strain $918-5$ c, and analysing the meiotic products. The CDC10 gene encodes a septin, one of the components of the ring of $10 \mathrm{~nm}$ microfilaments (Longtine et al., 1996). Mutations in the septins are known to prevent cytokinesis and to promote hyperpolar growth after bud emergence, leading to a characteristic cell division cycle phenotype (Hartwell, 1971; Adams \& Pringle, 1984). Segregants in which both bem2 and $c d c 10$ mutations occur simultaneously grew very slowly even at the permissive temperature (data not shown), suggesting that both genes could be involved in pathways supporting the same functions. The shift to $37^{\circ} \mathrm{C}$ led to the coexpression of both mutations, resulting in a particular 

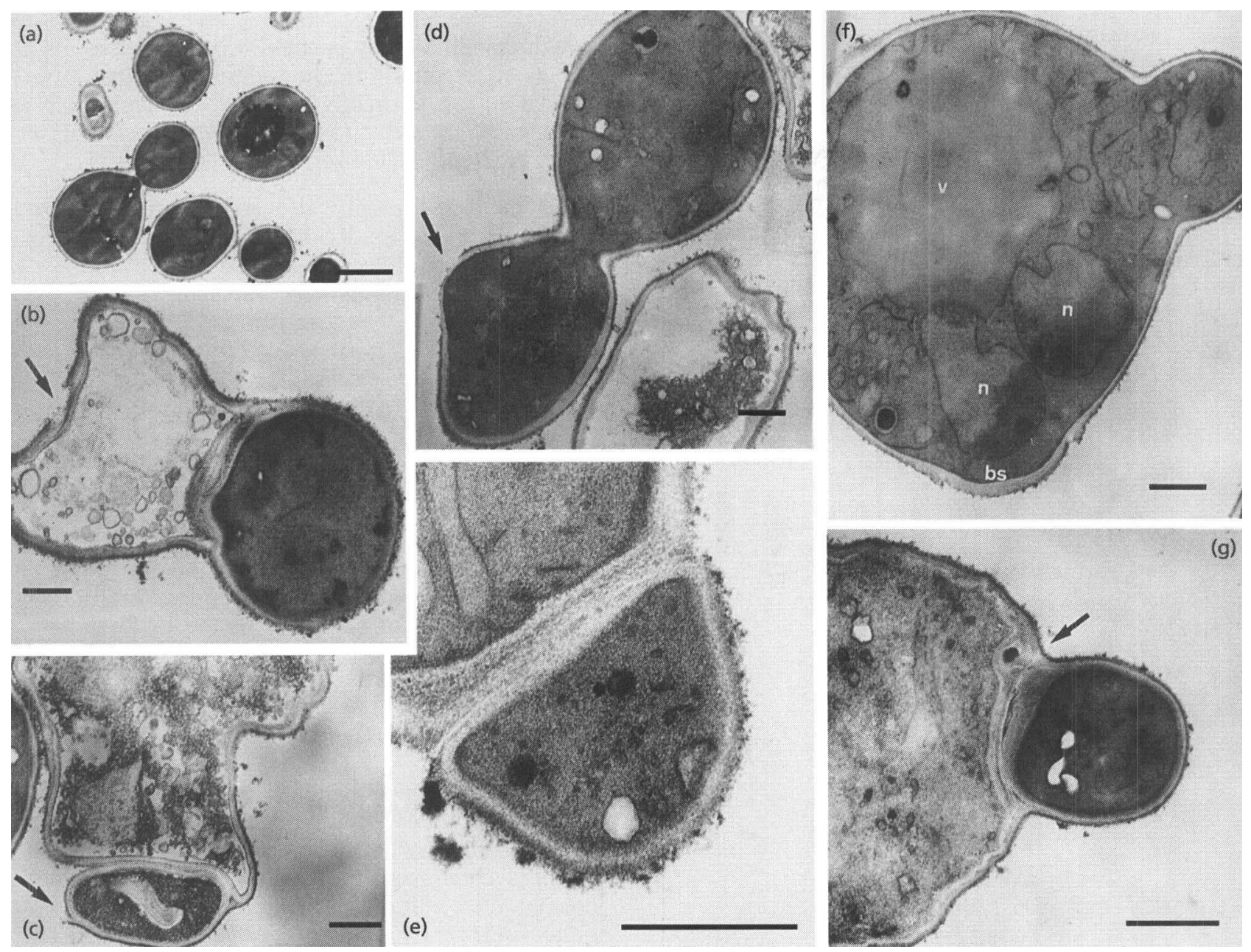

(e)

Fig. 5. Transmission electron microscopy images of the bem2-21/bem2-21 strain V918 showing its characteristic morphogenetic defects. For comparison, the wild-type strain D1 is shown (a). In (b) an intact cell (right) and a lysed cell (left) are attached by a thick septum. The lysed cell shows a discontinuous area in the cell wall. At this point and in the septum the cell wall apparently exhibits an abnormal double-layer structure. (c) A huge lysed cell which is still semiattached to a smaller cell. The two cells are separated by an aberrant wide septum that seems to disjoin in an asymmetrical fashion (arrow). The cell in (d) shows a thin area in the cell wall glucan which gives the cell a 'bumpy' appearance (arrow). This is probably a stage preceding cell lysis. In (e) a small bud, apparently lacking a nucleus, seems to be precociously separated by an abnormally thick septum. ( $f$ ) A swollen budding cell containing two nuclei ( $n$ ) and a large vacuole (v). Both the constriction at the bud and the bud scar (bs) at the bottom of the picture are abnormally wide. (g) Another thick septum in which a cytoplasmic inclusion is observed (arrow) separates a lysed cell and a small intact bud. Bars, $1 \mu \mathrm{m}$.

terminal phenotype of huge cells in which a general depolarization still permitted the apical growth phenotype caused by the septin mutation (Fig. 7a, b, c).

Under the conditions given by Gimeno et al. (1992) for filamentous growth in $S$. cerevisiae diploid strains, our wild-type diploid D1 was able to develop elongated cells, as described by those authors, although cell separation seemed complete and, thus, no actual filaments could be observed. We tested the ability of a V918 bem2-21 homozygous strain to form long cells under these conditions; such forms appeared in the same proportion as observed for the wild-type (Fig. 7d, e), although they were often larger. Thus, we concluded that the morphogenetic defect observed in bem2-21 does not preclude apical polarization for the development of elongated cells in conditions of limiting nitrogen source.

\section{DISCUSSION}

We have isolated the BEM2 gene by complementation of an autolytic lyt 3 mutant and analysed the phenotype that may cause cell lysis in our lyt3 (bem2-21) mutants. Our results show that these mutants indeed have an impaired cell wall that promotes cell fragility in both the mitotic and the meiotic cycles. Our observations on the morphogenesis of bem2-21 mutants add novel aspects to those reported by other groups who have worked with different bem 2 mutant alleles. According to our results and those obtained by others, a dysfunction in this gene 

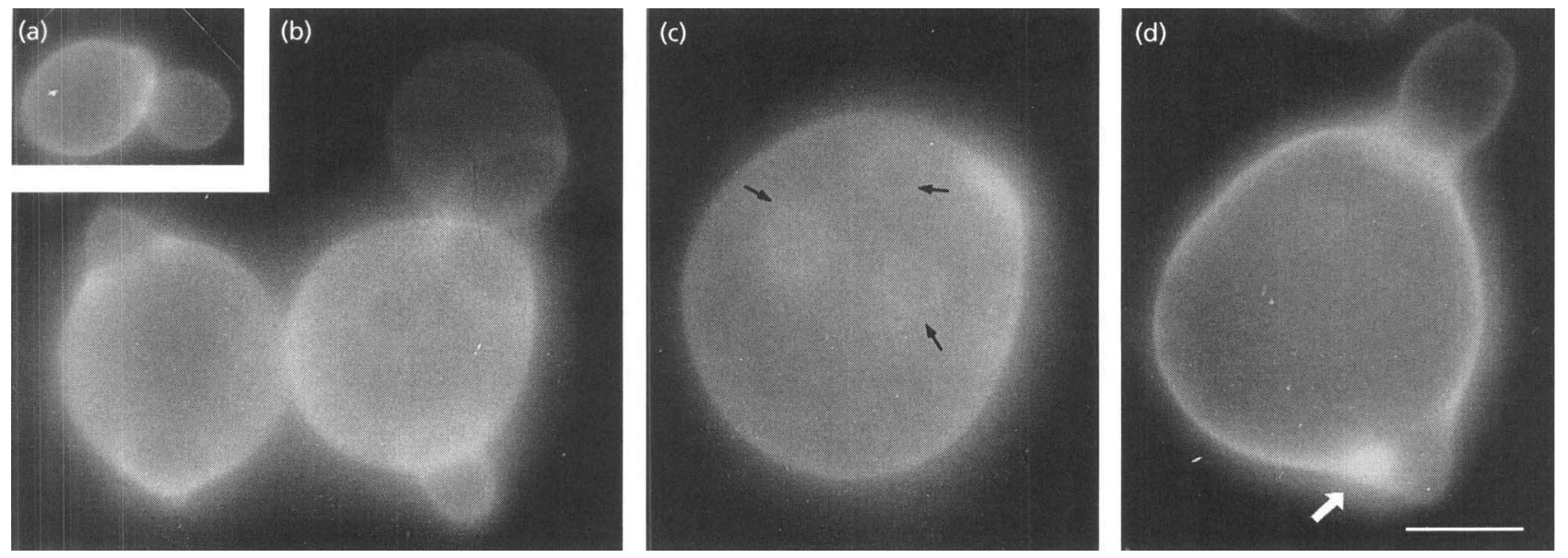

Fig. 6. Calcofluor white staining for the detection of chitin-rich areas in the cell wall. In a wild-type strain (S288C, a), chitin is concentrated at the bud scars and constriction rings of the proximal pole of the cells. In a bem2-21 mutant (strain 918-8a) some bud scars are abnormally wide and leave a particularly conspicuous birth scar in the daughter cell (b, cell in the upper right corner). Also, scars are not adjacent to each other and not concentrated at a particular pole (c, arrows). Small buds often display dense patches of chitin instead of a normal constriction (d, arrow). Bar, $5 \mu \mathrm{m}$ (magnification the same for each panel).
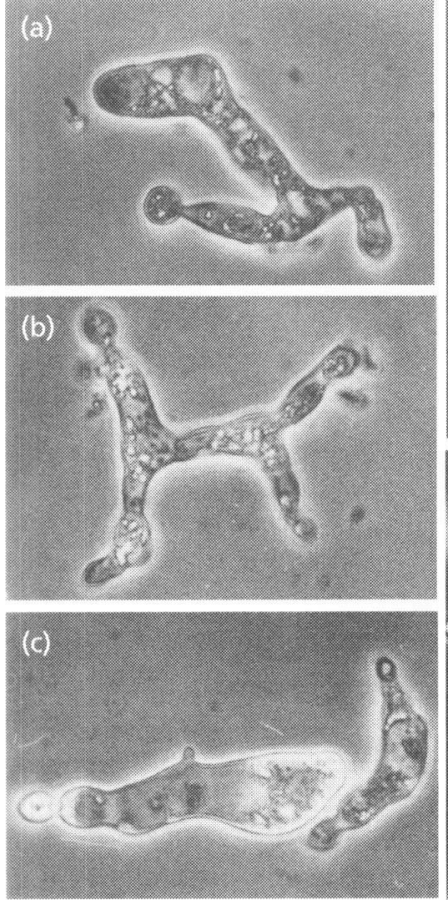
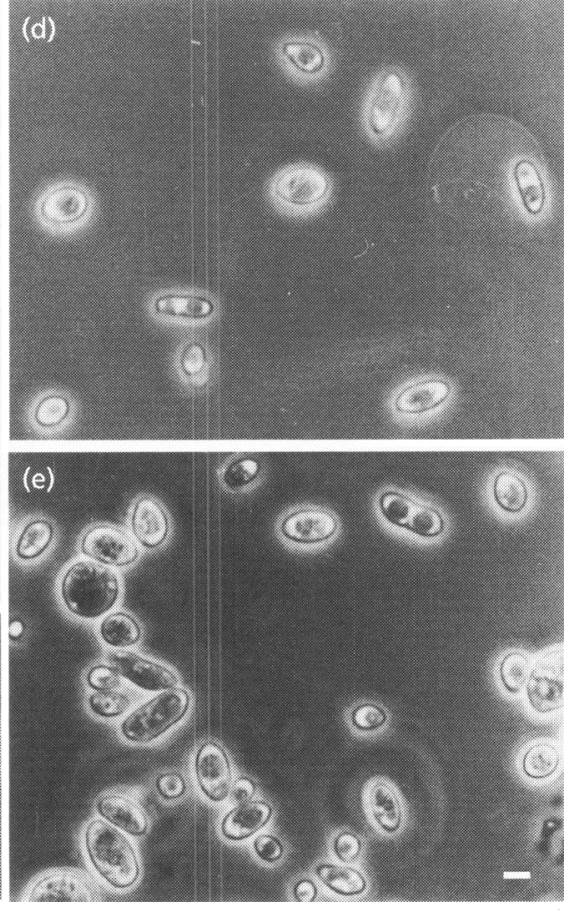

Fig. 7. $(a, b, c)$ Effect of simultaneous hyperpolarization of growth due to a cdc10 mutation and depolarization caused by the bem2-21 mutation. After incubation at $37^{\circ} \mathrm{C}$, gigantic cells with areas of hyperpolar growth appear. (d, e) Cell elongation induced by incubation of diploids in lownitrogen medium at $24^{\circ} \mathrm{C}$ persists in a bem2-21 background (d, D1 wild-type strain; e, V918 bem2-21/bem2-21 strain). Bar, $5 \mu \mathrm{m}$ (magnification the same for each panel). results in large multinucleate cells (Bender \& Pringle, 1991; Chan \& Botstein, 1993; Kim et al., 1994; Peterson et al., 1994; Wang \& Bretscher, 1995). Sorbitol (1 M) partially rescues cell lysis during cell division and allows sporulation of multinucleate cells, leading to the development of asci containing multiple spores.

The current hypothesis is that Bem2p is an important constituent of the complex mechanisms that regulate the polarization of growth for bud emergence (Bender \& Pringle, 1991; Zheng et al., 1994). An error in such mechanisms would lead to the depolarization of growth, which eventually causes an abnormal isotropic growth of the mother cell through cell cycle progression. Despite the lack or impairment of bud emergence, nuclear division proceeds, giving rise to multinucleate cells. In fact, a bem 2 allele was characterized in a search for increase-in-ploidy mutants (Chan \& Botstein, 1993).

The BEM2 gene encodes a GAP (GTPase-activating protein) which seems to act quite specifically on the small GTPase Rho1p, and perhaps on Rho2p as well 
(Kim et al., 1994). GAPs favour the GDP-bound conformation of the Ras superfamily GTPases (in which the Rho family is included) thus inactivating them, since their active conformation is the GTP-bound one. Rho1p seems to play a role in the maintenance of polarized growth in the initial stages of the budding process (Madaule et al., 1987), probably modulating the dynamics of the actin cytoskeleton by means of its interactions with the BNI1 gene product (Kohno et al., 1996) and with the protein kinase $C$ encoded by the PKC1 gene (Nonaka et al., 1995). Pkc1 acts upstream of a MAP kinase cascade essential for cell integrity in the same stages of cell cycle (Zarzov et al., 1996). Overexpression of the RHO1 gene (Yamochi et al., 1994) causes a pattern of morphogenetic defects reminiscent of the bem 2 mutant phenotype described in this work and by others (Bender \& Pringle, 1991; Kim et al., 1994; Peterson et al., 1994; Wang \& Bretscher, 1995), suggesting that, indeed, the role of Bem $2 p$ is to negatively regulate the activation of this small Rho GTPase. Nevertheless, we have found that the morphogenetic effects caused by a lack of Bem2 function are not affected either by overexpression of the MAPK in the pathway below, Slt2, or by the deletion of the SLT2 gene (data not shown). This suggests that Rho1 regulation probably influences morphogenesis by pathways different from the Pkc1-led phosphorylation cascade.

Rho1p localizes specifically to the sites of polarized growth, and such localization depends on the function of Cdc42p (Yamochi et al., 1994). The bem 2 mutant phenotype resembles that of $c d c 42^{\text {ts }}$ mutants (Adams $e t$ al., 1990), so the BEM2-encoded GAP could be involved not only in the control of Rholp activation but in its localization as well. We have observed that the actin cytoskeleton is delocalized in our bem2-21 mutants by fluorochrome-conjugated phalloidin staining (data not shown) in a way identical to previous descriptions of other bem 2 mutants (Bender \& Pringle, 1991; Wang \& Bretscher, 1995). Wang \& Bretscher (1995) studied the tubulin cytoskeleton in bem 2 mutants and also found an irregular distribution of microtubules. It is not clear whether this is a secondary effect of the morphogenetic defect or whether Bem $2 p$ could really form part of an anchorage site for microtubules in the polarized areas, but in any case this must be the cause of nuclear mislocalization in these mutants.

The data presented so far by several groups provide evidence that Bem2p functions in the control of cytoskeletal reorganization for bud emergence (Peterson $e t$ al., 1994; Wang \& Bretscher, 1995). We have analysed the impact of these phenomena in cell integrity. Our results suggest that the cell wall in bem 2 mutants has a reduced protective ability, on the basis of an enhanced susceptibility to both physical and chemical aggressions, and hypersusceptibility to cell-wall-related antifungal drugs and to other drugs which have intracellular targets, implying an alteration in cell surface permeability. We propose three non-exclusive hypotheses to explain the defect in cell integrity and morphogenesis in bem 2 mutants.
A first possibility is that Bem $2 p$ may be essential not only for the positioning of the morphogenetic mechanisms for cell wall biogenesis (that is, the actin cortical cytoskeleton) at the polarity sites but also for the control of glucan synthesis itself. It seems clear that Bem2 is a negative modulator of Rho1 (Peterson et al., 1994; Kim et al., 1994), which constitutes a regulatory subunit of the 1,3- $\beta$-glucan synthase complex (Drgonová et al., 1996; Qadota et al., 1996). A failure in the Rho1-GAP function should lead to a hyperactivated, or at least deregulated, Rho1. GTP-bound Rho1 stimulates glucan synthesis, so in the absence of a functional Rho1-GAP (Bem $2 p$ ), the activated form would be predominant and glucan synthesis would be constitutively activated. This might lead to the generation of an abnormal cell wall. The specific consequences of such a phenomenon in cell wall composition $(1,3-\beta$-glucan $/ 1,6-\beta$-glucan proportion, polymer cross-linking, etc.) is not predictable with the information we have so far. We report here the existence of occasional double-layered or thin areas and abnormally thick septa in bem 2 mutants (Figs 5 and 6), although these defects are local and in most areas of the cell wall we have not observed an altered architecture by electron microscopy (Fig. 5). Mutants in other glucan synthase subunits, different from Rho1, such as Fks1, exhibit a phenotype of resistance to echinocandin and papulacandin (Douglas et al., 1994; Castro et al., 1995), so it is conceivable that the hypothetical hyperactivation of the synthase in bem 2 mutants would cause the opposite effect. Consistent with this, we have taken advantage of the hypersusceptibility to echinocandin of our mutant for the isolation of the BEM2 gene.

A second possibility is that cell wall fragility is just an indirect effect of the depolarization of the actin cytoskeleton. Although this has not been demonstrated, it seems logical to conjecture that an altered actin cortical cytoskeleton would cause failures in polarized secretion that could affect the composition and architecture of the cell wall. Favouring this hypothesis, mutants in several actin-cytoskeleton-related genes (MYO2, TPM1, VRP1, END3) (Johnston et al., 1991; Liu \& Bretscher, 1992; Donnelly et al., 1993; Bénédetti et al., 1994) have been reported to show an abnormal pattern of chitin distribution in the cell wall. In addition, Gabriel \& Kopecká (1995) have shown that a certain actin mutant, with a phenotype reminiscent of that of bem 2 mutants, exhibits an anomalous cell wall architecture. In any case, our electron microscopy images of bem2-21 mutants show less severe damage to the cell wall architecture than those of the act 1 mutant presented by these authors.

A third possibility, which does not exclude the other two, is that the reduced protective ability of the cell wall in bem 2 mutants is due to the existence of nascent wall all around the cell surface. It is reasonable to think that cell wall in active growth areas has a relaxed structure that allows the incorporation of new polymers. This situation must be extreme at the moment of bud emergence, since the morphogenetic machinery is con- 
centrated at the incipient budding site. The existence of these hypothetical weak regions in the cell wall in growing areas would explain the enhanced resistance of stationary-phase (non-budded) cells as compared to exponential-phase (budded) cells to enzymic degradation of the cell wall in all the wild-type strains tested (Fig. 4a, b). The phenotypic expression of bem2 mutations implies a delocalization of the bud emergence site and a distribution of the same morphogenetic machinery all around the cell surface. Thus, it is likely that these weakened areas, rich in nascent wall, are distributed around the whole cell surface, producing a cell wall which would be mostly immature. This would explain not only the enhanced susceptibility of these cells to Zymolyase exposure or physical attack, but also the hypersensitivity to drugs which have an intracellular target, like 5-fluorocytosine, ketoconazole or benomyl, on the basis of an increased cell surface permeability.

Cell integrity basically depends on the development of a functional cell surface. Surprisingly, the search for genes using strategies based on autolytic mutants is allowing the isolation of signal-transduction-related genes like SLT2 (Torres et al., 1991) or BEM2 rather than cellwall-specific biosynthetic enzymes. Our results suggest that the pathways that regulate morphogenesis and, especially, its coordination with other events in the cell cycle, are essential for proper cell wall biosynthesis, and that a failure in these processes is reflected in the development of an altered and non-functional cell wall.

\section{ACKNOWLEDGEMENTS}

Thanks to Dr Alberto Álvarez for the flow cytometry analyses, Craig Thompson for the genomic library, Maribel GarcíaSáez for the automatic sequencing, Alan Bender for strains and discussion, and María Molina and Humberto Martín for comments and advice. This work was supported by grant PB91-919-01 from Dirección General de Investigación Científica y Técnica (MEC), grant BIO95-0303 (CICYT) and grant BIOT-CT90-165 from the EC (Bridge Programme).

\section{REFERENCES}

Adams, A. \& Pringle, J. (1984). Relationship of actin and tubulin distribution to bud growth in wild-type and morphogenetic mutant Saccharomyces cerevisiae. J Cell Biol 98, 934-945.

Adams, A., Johnson, D. I., Longnecker, R. M., Sloat, B. F. \& Pringle, J. R. (1990). CDC42 and CDC43, two additional genes involved in budding and the establishment of cell polarity in Saccharomyces cerevisiae. J Cell Biol 111, 131-142.

Ausubel, F. M., Kingston, R. E., Brent, R., Moore, D. D., Seidman, J. G., Smith, J. A. \& Struhl, K. (1993). Current Protocols in Molecular Biology. New York: Greene Publishing Associates/ Wiley Interscience.

Ballou, L., Hitzeman, R. A., Lewis, M. S. \& Ballou, C. E. (1991). Vanadate-resistant yeast mutants are defective in protein glycosylation. Proc Natl Acad Sci USA 88, 3209-3212.

Bender, A. \& Pringle, J. R. (1991). Use of a screen for synthetic lethal and multicopy suppressee mutants to identify two new genes involved in morphogenesis in Saccharomyces cerevisiae. Mol Cell Biol 11, 1295-1305.

Bénédetti, H., Raths, S., Crausaz, F. \& Riezman, H. (1994). The
END3 gene encodes a protein that is required for the internalization step of endocytosis and for actin cytoskeleton organization in yeast. Mol Biol Cell 5, 1023-1037.

Cabib, E. \& Duran, A. (1975). Simple and sensitive procedure for screening yeast mutants that lyse at nonpermissive temperatures. J Bacteriol 124, 1604-1606.

Castro, C., Ribas, J. C., Valdivieso, M. H., Varona, R., del Rey, F. \& Durán, A. (1995). Papulacandin B resistance in yeast: isolation and characterization of $P B R 1$, a gene involved in $(1,3) \beta$-D-glucan synthesis in Saccharomyces cerevisiae. J Bacteriol 177, 5732-5739.

Chan, C. S. M. \& Botstein, D. (1993). Isolation and characterization of chromosome-gain and increase-in-ploidy mutants in yeast. Genetics 135, 677-691.

Chen, G.-C., Zheng, L. \& Chan, C. S. M. (1996). The LIM domaincontaining Dbm1 GTPase-activating protein is required for normal cellular morphogenesis in Saccharomyces cerevisiae. Mol Cell Biol 16, 1376-1390.

Cid, v. J., Sanchez, M. \& Nombela, C. (1994). Characterization of thermosensitive autolytic mutants from diploid Saccharomyces cerevisiae. Microbiology 140, 559-568.

Cid, V. J., Durán, A., del Rey, F., Snyder, M., Nombela, C. \& Sánchez, M. (1995). Molecular basis of cell integrity and morphogenesis in Saccharomyces cerevisiae. Microbiol Rev 59, 345-386.

Donnelly, S. F. H., Pocklington, M. J., Pallotta, D. \& Orr, E. (1993). A proline-rich protein, verprolin, involved in cytoskeletal organization and cellular growth in the yeast Saccharomyces cerevisiae. Mol Microbiol 10, 585-596.

Douglas, C. M., Marrinan, W. L., Li, W. \& Kurtz, M. B. (1994). A Saccharomyces cerevisiae mutant with echinocandin-resistant 1,3- $\beta$-D-glucan synthase. J Bacteriol 176, 5686-5696.

Drgonová, J., Drgon, T., Tanaka, K., Kollár, R., Chen, G.-C., Ford, R. A., Chan, C. S. M., Takai, Y. \& Cabib, E. (1996). Rho1p, a yeast protein at the interface between cell polarization and morphogenesis. Science 272, 277-279.

Elledge, S. J. \& Davis, R.W. (1988). A family of versatile centromeric vectors designed for use in the sectoring-shuffle mutagenesis assay in Saccharomyces cerevisiae. Gene 70, 303-312.

Gabriel, M. \& Kopecká, M. (1995). Disruption of the actin cytoskeleton in budding yeast results in formation of an aberrant cell wall. Microbiology 141, 891-899.

Gimeno, C. J., Ljungdahl, P. O., Styles, C. A. \& Fink, G. R. (1992). Unipolar cell divisions in the yeast Saccharomyces cerevisiae lead to filamentous growth: regulation by starvation and RAS. Cell 68, 1077-1090.

Hartwell, L. H. (1971). Genetic control of cell division cycle in yeast. IV. Genes controlling bud emergence and cytokinesis. Exp Cell Res 69, 265-276.

Healy, A. M., Zolnierowicz, S., Stapleton, A. E., Goebl, M., DePaoli-Roach, A. A. \& Pringle, J. R. (1991). CDC55, a Saccharomyces cerevisiae gene involved in cellular morphogenesis: identification, characterization, and homology to the B subunit of mammalian type $2 \mathrm{~A}$ protein phosphatase. Mol Cell Biol 11, 5767-5780.

Johnston, G. C., Prendergast, J. A. \& Singer, R. A. (1991). The Saccharomyces cerevisiae MYO2 gene encodes an essential myosin for vectorial transport of vesicles. J Cell Biol 113, 539-551.

Kim, Y.-J., Francisco, L., Chen, G.-C., Marcotte, E. \& Chan, C. S. M. (1994). Control of cellular morphogenesis by the Ipl2/Bem2 GTPase-activating protein: possible role of protein phosphorylation. J Cell Biol 127, 1381-1384.

Klis, F. M. (1994). Cell wall assembly in yeast. Yeast 10, 851-869. 
Kohno, H., Tanaka, K., Mino, A., Umikawa, M., Imamura, H., Fujiwara, T., Fujita, Y., Hotta, K., Qadota, H., Watanabe, T., Ohya, Y. \& Takai, Y. (1996). Bnilp implicated in cytoskeletal control is a putative target of Rho1p small GTP binding protein in Saccharomyces cerevisiae. EMBO J 15, 6060-6068.

Kuo, S. C. \& Lampen, J. O. (1974). Tunicamycin - an inhibitor of yeast glycoprotein synthesis. Biochem Biophys Res Commun 58, 287-295.

Lee, K. S., Irie, K., Gotoh, Y., Watanabe, Y., Araki, H., Nishida, E., Matsumoto, K. \& Levin, D. E. (1993). A yeast mitogen-activated protein kinase homolog (Mpk1p) mediates signalling by protein kinase C. Mol Cell Biol 13, 3067-3075.

Liu, H. \& Bretscher, A. (1992). Characterization of TPM1 disrupted yeast cells indicates an involvement of tropomyosin in directed vesicular transport. J Cell Biol 118, 285-299.

Longtine, M. S., DeMarini, D., Valencik, M. L., Al-Awar, O. S., Fares, H., De Virgilio, C. \& Pringle, J. R. (1996). The septins: roles in cytokinesis and other processes. Curr Opin Cell Biol 8, 106-119.

Madaule, P., Axel, R. \& Myers, A. M. (1987). Characterization of two members of the rbo gene family from the yeast Saccharomyces cerevisiae. Proc Natl Acad Sci USA 84, 779-783.

Martin, H., Arroyo, J., Sanchez, M., Molina, M. \& Nombela, C. (1993). Activity of the yeast MAP kinase homologue Slt2 is critically required for cell integrity at $37^{\circ} \mathrm{C}$. Mol Gen Genet 241, 177-184.

Masuda, T., Tanaka, K., Nonaka, H., Yamochi, W., Maeda, A. \& Takai, Y. (1994). Molecular cloning and characterization of yeast Rho GDP dissociation inhibitor. J Biol Chem 269, 19713-19718.

Miret, J. J., Solari, A. J., Barderi, P. A. \& Goldemberg, S. H. (1992). Polyamines and cell wall organization in Saccharomyces cerevisiae. Yeast 8, 1033-1041.

Mulholland, J., Preuss, D., Moon, A., Wong, A., Drubin, D. \& Botstein, D. (1994). Ultrastructure of the yeast actin cytoskeleton and its association with the plasma membrane. J Cell Biol 125, 381-391.

Nonaka, H., Tanaka, K., Hirano, H., Fujiwara, T., Kohno, H., Umikawa, M., Mino, A. \& Takai, Y. (1995). A downstream target of RHO1 small GTP-binding protein is PKC1, a homolog of protein kinase $C$, which leads to activation of the MAP kinase cascade in Saccharomyces cerevisiae. EMBO J 14, 5931-5938.

Ozaki, K., Tanaka, K., Imamura, H., Hiraha, T., Kameyama, T., Nonaka, H., Hirano, H., Matsuura, Y. \& Takai, T. (1996). Rom1p and Rom $2 p$ are GDP/GTP exchange proteins (GEPs) for the Rho1p small GTP binding protein in Saccharomyces cerevisiae. EMBO J 15, 2196-2207.

Paravicini, G., Cooper, M., Friedli, L., Smith, D. J., Carpentier, J. L., Klig, L. S. \& Payton, M. A. (1992). The osmotic integrity of the yeast cell requires a functional PKC1 gene product. Mol Cell Biol $12,4896-4905$.
Peterson, J., Zheng, Y., Bender, L., Myers, A., Cerione, R. \& Bender, A. (1994). Interactions between the bud emergence proteins Bem 1p and Bem $2 \mathrm{p}$ and Rho-type GTPases in yeast. J Cell Biol 127, 1395-1406.

Qadota, H., Python, C. P., Inoue, S. B., Arisawa, M., Anraku, Y., Zheng, Y., Watanabe, T., Levin, D. E. \& Ohya, Y. (1996). Identification of yeast Rho1p GTPase as a regulatory subunit of 1,3-beta-glucan synthase. Science 272, 279-281.

Ridley, A. J. (1995). Rho-related proteins: actin cytoskeleton and cell cycle. Curr Opin Genet Dev 5, 24-30.

Sambrook, J., Fritsch, E. F. \& Maniatis, T. (1989). Molecular Cloning: a Laboratory Manual, 2nd edn. Cold Spring Harbor, NY: Cold Spring Harbor Laboratory.

Schmidt, A., Bickle, M., Beck, T. \& Hall, M. N. (1997). The yeast phosphatidylinositol kinase homolog TOR2 activates RHO1 and RHO2 via the exchange factor ROM2. Cell 88, 531-542.

Sikorski, R. S. \& Hieter, P. (1989). A system of shuttle vectors and yeast host strains designed for efficient manipulation of DNA in Saccharomyces cerevisiae. Genetics 122, 19-27.

Sloat, B. F., Adams, A. \& Pringle, J. R. (1981). Roles of the CDC24 gene product in cellular morphogenesis during the Saccharomyces cerevisiae cell cycle. J Cell Biol 89, 395-405.

Stevenson, B. J., Ferguson, B., De Virgilio, C., Bi, E., Pringle, J. R., Ammerer, G. \& Sprague, G. F., Jr (1995). Mutation of RGA1 which encodes a putative GTPase-activating protein for the polarityestablishment protein Cdc42p, activates the pheromone-response pathway in the yeast Saccharomyces cerevisiae. Genes Dev 9, 2949-2963.

Torres, L., Martin, H., Garcia-Saez, M. I., Arroyo, J., Molina, M., Sanchez, M. \& Nombela, C. (1991). A protein kinase gene complements the lytic phenotype of Saccharomyces cerevisiae lyt2 mutants. Mol Microbiol 5, 2845-2854.

Wang, T. \& Bretscher, A. (1995). The rho-GAP encoded by BEM2 regulates cytoskeletal structure in budding yeast. Mol Biol Cell 6, 1011-1024.

Yamochi, W., Tanaka, K., Nonaka, H., Maeda, A., Musha, T. \& Takai, Y. (1994). Growth site localization of Rho1 small GTPbinding protein and its involvement in bud formation in Saccharomyces cerevisiae. J Cell Biol 125, 1077-1093.

Zarzov, P., Mazzoni, C. \& Mann, C. (1996). The SLT2(MPK1) MAP kinase is activated during periods of polarized cell growth in yeast.

Zheng, Y., Cerione, R. \& Bender, A. (1994). Control of the yeast bud-site assembly GTPase Cdc42. J Biol Chem 269, 2369-2372.

Received 8 May 1997; revised 4 September 1997; accepted 17 September 1997. 